\title{
Diversidade genética de dourado utilizado em programas de repovoamento no rio Paranapanema
}

\author{
Patrícia Cristina Gomes ${ }^{(1)}$, Ricardo Pereira Ribeiro(2), Rodolfo Nardez Sirol(3), Nelson Maurício Lopera-Barrero(4), \\ Heden Luiz Marques Moreira( ${ }^{(5)}$, Jayme Aparecido Povh ${ }^{(4)}$, Claudete Aparecida Mangolin ${ }^{(6)}$, \\ Lauro Vargas ${ }^{(2)}$, Carolina Bespalhok Jacometo ${ }^{(5)}$ e Danilo Pedro Streit Júnior(7)
}

\begin{abstract}
(1)Fundação de Apoio à Pesquisa e ao Desenvolvimento do Agronegócio, Rua Paranaguá, no 1.077, CEP 86020-030 Londrina, PR. E-mail: patriciacgomes.peixegen@gmail.com (2)Universidade Estadual de Maringá, Departamento de Zootecnia, Núcleo de Pesquisa PeixeGen, Avenida Colombo, no 5.790, Bloco J57, Sala 8B, CEP 87020-900 Maringá, PR. E-mail: ricardo.peixegen@gmail.com, Ivargas@uem.br ${ }^{(3)}$ Companhia Paulista de Força e Luz - Geração, Rodovia Campinas-Mogi Mirim, Km 2,5, CEP $13088-900$ Campinas, SP. E-mail: rnsirol@cpfl.com.br (4)Universidade Federal de Mato Grosso, Instituto de Ciências Agrárias e Tecnológicas, Rodovia RondonópolisGuiratinga, Km 6, CEP 78735-910 Rondonópolis, MT. E-mail: nelson.peixegen@gmail.com, jayme.peixegen@gmail.com (5)Universidade Federal de Pelotas, Instituto de Biologia, Departamento de Zoologia e Genética, Campus Universitário s/no, CEP $96010-900$ Pelotas, RS. E-mail: heden.luiz@gmail.com, carolina.peixegen@gmail.com ${ }^{(6)}$ Universidade Estadual de Maringá, Departamento de Biologia Celular e Genética, Avenida Colombo, no 5.790, Bloco H67, CEP 87020-900 Maringá, PR. E-mail: cmangolin@uem.br (7)Universidade Federal do Rio Grande do Sul, Departamento de Zootecnia, Avenida Bento Gonçalves, no 7.712, CEP 91540-000 Porto Alegre, RS. E-mail: danilo.streit@ufrgs.br
\end{abstract}

Resumo - O objetivo deste trabalho foi avaliar a diversidade genética de um estoque de Salminus brasiliensis utilizado em programas de repovoamento do rio Paranapanema, por meio do marcador RAPD. Dez reprodutores (cinco machos e cinco fêmeas) e sua progênie (40 larvas e 40 alevinos) foram analisados. Os oito iniciadores analisados produziram 96 fragmentos, dos quais $81,2 \%$ foram polimórficos. Houve diferença significativa na frequência de 32 dos 96 fragmentos, com a presença de um fragmento exclusivo nos alevinos. O índice de Shannon, a percentagem de fragmentos polimórficos e a distância e a identidade genética mostraram menor divergência genética entre os reprodutores e as larvas, além de diminuição da variabilidade nos alevinos. A divergência genética foi menor nos alevinos em comparação às larvas e aos reprodutores. A análise de variância molecular mostrou que a maior parte da variação está dentro de cada grupo (90,05\%) e não entre os grupos $(9,95 \%)$. O estoque de reprodutores apresenta alta variabilidade genética e houve diferenciação genética entre a fase de larva e alevino.

Termos para indexação: Salminus brasiliensis, marcador molecular, peixe, RAPD, programas de repovoamento.

\section{Genetic diversity of dourado used in stock enhancement programs in the Paranapanema River}

\begin{abstract}
The objective of this work was to estimate by RAPD markers the genetic diversity of a Salminus brasiliensis lot used in stock enhancement programs in the Paranapanema River, Paraná, Brazil. Ten broodstocks (five males and five females) and their progeny (40 larvae and 40 fingerlings) were analyzed. Eight analyzed primers produced 96 fragments, of which $81.2 \%$ were polymorphic. There was significant difference in the frequency of 32 out of the 96 fragments, with the presence of an exclusive fragment in the fingerlings. The Shannon index, the percentage of polymorphic fragments, and the genetic distance and identity showed less genetic divergence between broodstocks and larvae, besides a decrease of genetic variability in the fingerlings. Genetic divergence was lower in the fingerlings in comparison to the larvae and broodstocks. The molecular variance results showed that most of the genetic variation is within $(90.05 \%)$ and not between groups $(9.95 \%)$. The broodstock lot has high genetic variability, and genetic differences were observed between the larval and fingerling stages.
\end{abstract}

Index terms: Salminus brasiliensis, molecular marker, fish, RAPD, stock enhancement programs.

\section{Introdução}

Salminus brasiliensis (Cuvier, 1816)(Actinopterygii: Characiformes, Characidae), conhecido popularmente como dourado, apresenta ampla distribuição geográfica no território brasileiro, principalmente na Bacia do Prata, formada pelos rios Paraguai, Paraná e Uruguai, e na Bacia do rio São Francisco (Barbieri et al., 2001; Lima et al., 2003; Zaniboni-Filho, 2004).

Nos últimos anos, tem-se observado um decréscimo na captura do dourado no rio Paranapanema (Lopes et al., 2007).

Uma importante medida para a conservação, não apenas dessa espécie, mas também de toda a fauna 
piscícola, é o desenvolvimento de programas de repovoamento (Sirol \& Britto, 2006). Esta medida vem sendo bastante questionada, uma vez que a perda da diversidade genética dos peixes destinados à soltura nos rios pode tornar essa prática contraproducente, o que acarreta perda da variabilidade genética da ictiofauna nativa (Agostinho et al., 2005; Povh et al., 2008). A diminuição da variabilidade genética pode causar perda de resistência às doenças e redução da capacidade de adaptação. Povh et al. (2008) destacam que a perda da variabilidade genética pode ocorrer em virtude do efeito fundador e da utilização de um baixo número efetivo de reprodutores; no entanto, um manejo reprodutivo adequado pode minimizar perdas genéticas na progênie.

O monitoramento da diversidade genética dos reprodutores e dos peixes que serão liberados no ambiente (Ortega-Villaizán Romo et al., 2006) é necessário para minimizar os efeitos negativos do repovoamento. Entre as técnicas moleculares, a de RAPD (Random Amplified Polymorphic DNA) tem sido utilizada com sucesso para a estimação da diversidade genética em populações (Pamponet et al., 2008), espécies e linhagens de peixes (Sanches \& Galetti Junior, 2007), e para o monitoramento genético de programas de conservação (Jacometo et al., 2010; Lopera-Barrero et al., 2010b).

O objetivo deste trabalho foi avaliar a diversidade genética de um estoque de $S$. brasiliensis utilizado em programas de repovoamento do rio Paranapanema, por meio do marcador RAPD.

\section{Material e Métodos}

O trabalho foi realizado em novembro de 2007, na Estação de Hidrologia e Aquicultura da Duke Energy International, localizada no Município de Salto Grande, SP $\left(23^{\circ} 10^{\prime} \mathrm{S}, 49^{\circ} 13^{\prime} \mathrm{W}\right)$, com o Laboratório de Biologia Molecular do Departamento de Zootecnia da Universidade Estadual de Maringá, Maringá, PR.

Foram utilizados dez reprodutores (cinco machos e cinco fêmeas) de $S$. brasiliensis, coletados aleatoriamente de uma população estocada há cinco anos nas instalações da Estação de Aquicultura e Hidrologia da Duke Energy International. Esses indivíduos foram provenientes de coletas realizadas nas escadas de transposição das usinas hidroelétricas de Canoas I $\left(22^{\circ} 56^{\prime} \mathrm{S}, 50^{\circ} 31^{\prime} \mathrm{W}\right)$ e Canoas II $\left(22^{\circ} 56^{\prime} \mathrm{S}\right.$, $\left.50^{\circ} 14^{\prime} \mathrm{W}\right)$, situadas no rio Paranapanema, no Estado de São Paulo.

Os dez reprodutores foram induzidos à reprodução seminatural, com extrato de hipófise de carpa, conforme descrito por Lopera-Barrero (2007). As fêmeas receberam 5,5 mg kg-1 do extrato, divididos em duas aplicações: $10 \%$ do total na primeira aplicação e, 12 horas depois, os $90 \%$ restantes. Os machos receberam 2,5 $\mathrm{mg} \mathrm{kg}^{-1}$ em dose única. Amostras de nadadeira caudal ( $0,5 \mathrm{~cm}$ aproximadamente) foram coletadas de todos os indivíduos, e, em seguida, armazenadas em microtubos de 1,5 mL, contendo álcool etílico $100 \%$, e estocadas em freezer a $-5^{\circ} \mathrm{C}$, para a posterior extração e amplificação do DNA.

Depois da indução hormonal, os reprodutores foram colocados em um tanque circular, com um raio de $5,1 \mathrm{~m}$ e $1,85 \mathrm{~m}$ de profundidade média, abastecido por fluxo de água contínuo $\left(131 \mathrm{~L} \mathrm{~s}^{-1}\right)$, em dois sentidos de vazão, para desova espontânea. Aproximadamente seis horas após a última indução $\left(260\right.$ horas a $\left.27^{\circ} \mathrm{C}\right)$, foi iniciada a coleta de ovos. O escoamento da água na porção central, mediante um cano de seis polegadas, permitiu o direcionamento dos ovos para uma estação coletora; os ovos foram vertidos em uma incubadora cilindro-cônica de captação de 200 L, com fluxo contínuo de água $\left(7 \mathrm{~L} \mathrm{~s}^{-1}\right)$, e, em seguida, foram levados a incubadoras individuais do tipo cilindro-cônicas. A percentagem de mortalidade dos reprodutores (fêmea/macho) usados nos acasalamentos foi definida um dia depois da reprodução.

Dois dias após a eclosão dos ovos, aproximadamente 200 larvas foram coletadas aleatoriamente de todas as incubadoras em horários diferentes e armazenadas em microtubos de $1,5 \mathrm{~mL}$, contendo álcool etílico $100 \%$. Destas larvas, 40 foram coletadas de forma aleatória para posterior extração e amplificação do DNA.

Também foram coletadas 40 amostras de nadadeira caudal $(0,5 \mathrm{~cm}$ aproximadamente) de alevinos com 30 dias de idade, estocados em tanques de $600 \mathrm{~m}^{2}$, que foram armazenadas em microtubos de 1,5 mL, contendo álcool etílico $100 \%$, para posterior extração e amplificação do DNA.

Para extração de DNA, foi utilizada a metodologia descrita por Lopera-Barrero et al. (2008). Em microtubos contendo as nadadeiras foram adicionados $550 \mu \mathrm{L}$ de tampão de lise $\left(50 \mathrm{mmol} \mathrm{L}^{-1}\right.$ de Tris- $\mathrm{HCl}, 50 \mathrm{mmol} \mathrm{L}^{-1}$ de EDTA e $100 \mathrm{mmol} \mathrm{L}^{-1} \mathrm{de}$ $\mathrm{NaCl})$, SDS a $1 \%$ e $7 \mu \mathrm{L}$ de proteinase $\mathrm{K}\left(200 \mu \mathrm{g} \mathrm{mL}^{-1}\right)$. 
As amostras foram incubadas em banho-maria a $50^{\circ} \mathrm{C}$ por 12 horas. O DNA foi precipitado com $600 \mu \mathrm{L}$ de solução de $\mathrm{NaCl}\left(5 \mathrm{~mol} \mathrm{~L}^{-1}\right)$ e centrifugado por $10 \mathrm{~min}$ a $12.000 \mathrm{rpm}$. O sobrenadante contendo o DNA foi transferido para novos microtubos $(600 \mu \mathrm{L})$, precipitado com $700 \mu \mathrm{L}$ de álcool etílico absoluto e incubado por 1 hora a $-20^{\circ} \mathrm{C}$. O DNA foi centrifugado e lavado com $700 \mu \mathrm{L}$ de álcool etílico a $70 \%$. Os péletes foram secos por aproximadamente $20 \mathrm{~min}$ à temperatura ambiente e posteriormente ressuspendidos em $80 \mathrm{~mL}$ de tampão TE (10 mmol L-1 de Tris, pH 8,0 e $1 \mathrm{mmol} \mathrm{L}^{-1}$ de EDTA) e tratados com $7 \mu \mathrm{L}$ de RNAse $\left(30 \mathrm{mg} \mathrm{mL}^{-1}\right)$ em banho-maria, a $37^{\circ} \mathrm{C}$ por 1 hora, e, em seguida, estocados no freezer a $-20^{\circ} \mathrm{C}$.

O DNA foi quantificado em espectrofotômetro Shimadzu UV-1601 (Shimadzu Corporation, Kyoto, Japão), com absorbância de $260 \mathrm{~nm}$. As amostras foram diluídas para concentração de $10 \mathrm{ng} \mu \mathrm{L}^{-1}$. Para conferir a qualidade do DNA, foi realizada eletroforese em gel de agarose a $1 \%$, conduzida em tampão TBE 1X (500 $\mathrm{mmol} \mathrm{L}^{-1}$ de Tris-HC1, $60 \mathrm{mmol} \mathrm{L}{ }^{-1}$ de ácido bórico e $83 \mathrm{mmol} \mathrm{L}^{-1}$ de EDTA), por uma hora a 70 volts.

As condições de amplificação foram baseadas em Williams et al. (1990), com algumas modificações. O DNA genômico foi amplificado em um volume de reação de $15 \mu \mathrm{L}$, com tampão Tris-KCl $1 \mathrm{X}$ (20 mmol L-1 de Tris-HCl, pH 8,4 e $50 \mathrm{mmol} \mathrm{L}^{-1}$ de $\mathrm{KCl}), 2,5 \mathrm{mmol} \mathrm{L}^{-1} \mathrm{de}_{\mathrm{MgCl}}, 0,46 \mathrm{mmol} \mathrm{L}^{-1}$ de iniciador (oligonucleotídeos), 0,2 $\mathrm{mmol} \mathrm{L}^{-1}$ de cada dNTPs, uma unidade de Taq DNA polimerase e $10 \mathrm{ng}$ de DNA molde. As reações de RAPD foram amplificadas em um termociclador Mastercycler Gradient (Eppendorf, Hamburgo, Alemanha), programado para 40 ciclos, com um passo inicial de desnaturação a $92^{\circ} \mathrm{C}$, por $4 \mathrm{~min}$, e um passo final de extensão a $72^{\circ} \mathrm{C}$, por 5 min. Cada ciclo foi constituído de $40 \mathrm{~s}$ a $92^{\circ} \mathrm{C}, 1 \mathrm{~min}$ e $30 \mathrm{~s} \mathrm{a} 40^{\circ} \mathrm{C}$ e 2 min a $72^{\circ} \mathrm{C}$.

Foram avaliados 60 iniciadores do Kit Operon (Operon Technologies Inc., Alameda, CA, EUA). Para avaliar os diferentes estoques, foram selecionados oito iniciadores, que apresentaram bom padrão de amplificação.

Os produtos de amplificação foram separados em gel de agarose a $1,4 \%$. Foram utilizados $15 \mu \mathrm{L}$ do produto amplificado e $2 \mu \mathrm{L}$ de tampão de amostra ( $40 \%$ de sacarose e $0,25 \%$ de azul de bromofenol) em eletroforese horizontal. A eletroforese foi conduzida em $70 \mathrm{~V}$ por 4 horas, em uma cuba horizontal, com uso do tampão TBE $1 \mathrm{X}\left(500 \mathrm{mmol} \mathrm{L}^{-1}\right.$ de Tris-HCl, $60 \mathrm{mmol} \mathrm{L}^{-1}$ de ácido bórico e $83 \mathrm{mmol} \mathrm{L}^{-1}$ de EDTA). Foi utilizado um controle negativo para cada reação, com sua amplificação executada ao adicionarem todos os componentes citados anteriormente, exceto o DNA alvo.

Para a revelação do gel, utilizou-se um banho de brometo de etídeo a $0,5 \mu \mathrm{g} \mathrm{mL}^{-1}$, por $30 \mathrm{~min}$. Posteriormente, os géis foram fotografados com o sistema EDAS (eletrophoresis documentation and analysis), 1D Image Analysis 3.5, (Kodak, Rochester, NY, EUA).

O tamanho dos fragmentos foi estimado em comparação ao padrão DNA Ladder de 100 pb (Invitrogen, Carlsbad, CA, EUA). A presença ou ausência de bandas de tamanhos moleculares idênticos (mesmo fragmento) foi usada para a construção de uma matriz de similaridade, em que 1, indica presença da banda no gel e 0 , ausência.

O índice de diversidade genética de Shannon e a percentagem de fragmentos polimórficos (critério de 95\%) foram obtidos com o programa PopGene 1.31 (Yeh et al., 1999). O programa TFPGA 1.3 (Miller, 1997) foi utilizado para determinar a distância e a identidade genética (Nei, 1978) entre os estoques e a frequência dos fragmentos, pelo teste exato (Raymond \& Rousset, 1995). O programa Arlequin 3.0 (Excoffier et al., 2005) foi utilizado para a análise de variância molecular; a significância deste teste foi verificada pelo método de permutações aleatórias, com 10.000 permutações. A divergência genética em cada estoque foi obtida com base no cálculo do coeficiente de Jaccard, pelo método de Monte Carlo, com o programa Mantel-Struct (Miller, 1999).

Uma vez que a distância de Nei não é métrica, a dispersão em coordenadas principais foi construída após correção de Lingoes, pelo programa DistPCoA (Legendre \& Anderson, 1998), e evidenciada por meio de um gráfico, com o uso do programa Statistica, versão 7.1, 2005 (Statsoft, 2005).

\section{Resultados e Discussão}

Todos os iniciadores selecionados produziram diferentes padrões de fragmentos RAPD. O número de fragmentos nítidos e reproduzíveis gerados por iniciador nos três estoques variou de 7 a 17 , e o 
tamanho dos produtos amplificados permaneceu entre 220 e $2.700 \mathrm{pb}$ (Tabela 1). Dos 96 fragmentos analisados para os 8 iniciadores randômicos, 78 foram polimórficos $(81,25 \%)$ e 18 monomórficos $(18,75 \%)$.

Foram observadas diferenças significativas na frequência de 32 dos 96 fragmentos (Tabela 2). Dois fragmentos com baixa frequência (menor que 0,1) foram observados nos parentais, sete nas larvas e um nos alevinos. Foram observados nas progênies 25 fragmentos ausentes, 5 nas larvas e 20 nos alevinos. Foram encontrados quatro fragmentos limitantes, um nos parentais e três nas larvas. Um fragmento exclusivo foi observado nos parentais (iniciador OPX06, $2.700 \mathrm{pb}$ ). A ausência de fragmentos excluídos e a presença de poucos fragmentos de baixa frequência caracterizaram variabilidade genética adequada no estoque de reprodutores. Fragmentos de baixa frequência e a ausência de fragmentos denotam perda de variabilidade genética nas larvas, mais acentuadamente nos alevinos.

A percentagem de fragmentos polimórficos (FP) e o índice de Shannon (IS) foram superiores nas progênies (larvas, 77,08\% e 0,4199, respectivamente; alevinos, $71,88 \%$ e 0,3708 , respectivamente) do que nos parentais $(51,04 \%$ e 0,2805 , respectivamente). A maior divergência genética nas larvas $(0,275)$ em relação aos parentais $(0,268)$ confirma a maior variabilidade dos indivíduos da progênie. De acordo com a análise de variância molecular (AMOVA), a maior parte da variação genética está dentro de cada grupo $(90,05 \%)$ e não entre os grupos $(9,95 \%)$ de $S$. brasiliensis (Tabela 3). As estimativas da identidade e da distância genética também evidenciaram que a variabilidade

Tabela 1. Iniciadores, sequências de nucleotídeos dos iniciadores (SN), percentagem de bases $\mathrm{G}+\mathrm{C}$, número de fragmentos (NF), número de fragmentos polimórficos (NFP) e tamanho dos fragmentos amplificados (TFA), para os parentais e a progênie de Salminus brasiliensis.

\begin{tabular}{lccccc}
\hline Iniciador & SN (3' 5') & G + C & NF & NFP & TFA $(\mathrm{pb})$ \\
\hline X-01 & CTG GGC ACG A & 70 & 16 & 15 & $220-2.700$ \\
X-06 & ACG CCA GAG G & 70 & 11 & 04 & $400-2.700$ \\
X-07 & GAG CGA GGC T & 70 & 13 & 13 & $600-2.700$ \\
X-09 & GGT CTG GTT G & 60 & 17 & 14 & $320-2.200$ \\
X-12 & TCG CCA GCC A & 70 & 08 & 04 & $750-2.100$ \\
X-13 & ACG GGA GCA A & 60 & 11 & 10 & $400-1.900$ \\
A-02 & TGC CGA GCT G & 70 & 13 & 12 & $380-1.800$ \\
A-16 & AGC CAG CGA A & 60 & 07 & 06 & $300-2.700$ \\
\hline Total & - & - & 96 & 78 & $220-2.700$ \\
\hline
\end{tabular}

genética dos parentais foi preservada na progênie, o que concorda com os resultados da frequência dos fragmentos.

Em geral, espera-se uma diminuição da variabilidade genética nos estoques mantidos em cativeiro, em consequência do efeito da seleção intencional e do acasalamento entre parentais (Lopera-Barrero et al., 2010a). Contudo, neste trabalho, o efeito gargalo não teve influencia, o que indica que o manejo reprodutivo foi adequado, com formação do estoque com suficiente variabilidade genética, e que a utilização de sistemas reprodutivos eficientes provavelmente permitiu

Tabela 2. Caracterização, tamanho (pb) e frequência dos fragmentos que apresentaram valores significativos pelo teste exato, para os parentais e a progênie de Salminus brasiliensis.

\begin{tabular}{|c|c|c|c|c|c|}
\hline \multirow[t]{3}{*}{ Iniciador } & \multirow{3}{*}{$\begin{array}{c}\text { Tamanho } \\
\text { (pb) }\end{array}$} & \multicolumn{3}{|c|}{ Frequência } & \multirow[t]{3}{*}{$\mathrm{P}^{(1)}$} \\
\hline & & \multirow[t]{2}{*}{ Parentais } & \multicolumn{2}{|c|}{ Progênie } & \\
\hline & & & Larvas & Alevinos & \\
\hline \multirow{5}{*}{ OPX01 } & 2.700 & 0,051 & 0,097 & 0,302 & 0,002 \\
\hline & 2.600 & 0,157 & 0,494 & 0,000 & 0,000 \\
\hline & 500 & 0,189 & 0,039 & 0,000 & 0,002 \\
\hline & 400 & 0,173 & 0,013 & 0,000 & 0,003 \\
\hline & 300 & 0,189 & 0,013 & 0,000 & 0,002 \\
\hline OPX06 & 2.700 & 0,194 & 0,000 & 0,000 & 0,001 \\
\hline \multirow{7}{*}{ OPX07 } & 2.700 & 0,051 & 0,293 & 0,000 & 0,001 \\
\hline & 2.500 & 0,163 & 0,526 & 0,000 & 0,001 \\
\hline & 2.072 & 0,452 & 1,000 & 0,000 & 0,000 \\
\hline & 1.900 & 0,106 & 0,613 & 0,476 & 0,002 \\
\hline & 1.700 & 0,367 & 0,726 & 0,000 & 0,001 \\
\hline & 1.000 & 0,367 & 0,842 & 0,842 & 0,001 \\
\hline & 800 & 0,225 & 0,646 & 0,000 & 0,000 \\
\hline \multirow{7}{*}{ OPX09 } & 2.200 & 0,553 & 1,000 & 0,000 & 0,002 \\
\hline & 2.072 & 0,776 & 0,526 & 0,000 & 0,004 \\
\hline & 2.000 & 0,163 & 0,776 & 0,842 & 0,000 \\
\hline & 1.000 & 0,476 & 0,258 & 0,000 & 0,003 \\
\hline & 800 & 0,311 & 0,106 & 0,000 & 0,001 \\
\hline & 500 & 0,367 & 0,553 & 0,120 & 0,002 \\
\hline & 320 & 0,258 & 0,025 & 0,000 & 0,001 \\
\hline \multirow{2}{*}{ OPX12 } & 2.100 & 0,225 & 0,000 & 0,552 & 0,002 \\
\hline & 2.072 & 0,225 & 0,000 & 0,552 & 0,002 \\
\hline \multirow{4}{*}{ OPX13 } & 1.900 & 0,452 & 1,000 & 0,000 & 0,001 \\
\hline & 1.100 & 0,452 & 0,000 & 0,842 & 0,002 \\
\hline & 700 & 0,163 & 0,225 & 0,500 & 0,002 \\
\hline & 500 & 0,293 & 0,367 & 0,613 & 0,001 \\
\hline \multirow{2}{*}{ OPA02 } & 480 & 0,209 & 0,051 & 0,000 & 0,001 \\
\hline & 380 & 0,194 & 0,013 & 0,000 & 0,001 \\
\hline \multirow{4}{*}{ OPA16 } & 2.700 & 0,430 & 0,414 & 0,000 & 0,000 \\
\hline & 2.500 & 0,324 & 0,134 & 0,000 & 0,000 \\
\hline & 1.400 & 1,000 & 0,258 & 0,367 & 0,000 \\
\hline & 1.300 & 0,225 & 0,000 & 0,014 & 0,000 \\
\hline
\end{tabular}

(1)Significância estatística. 
manter o "pool" genético do estoque de reprodutores e, consequentemente, da sua progênie.

É possível que a utilização do sistema reprodutivo seminatural tenha influenciado a preservação da variabilidade genética, uma vez que esse sistema reduz o direcionamento, a seleção não intencional e a mortalidade de reprodutores, o que permite que um maior número de reprodutores participe durante o acasalamento (Lopera-Barrero et al., 2010c). Ao analisar a variabilidade genética de progênies de Brycon orbignyanus no sistema reprodutivo seminatural, Lopera-Barrero et al. (2010c) constataram heterozigosidade media maior na progênie do que nos parentais. Resultados similares foram encontrados por Povh et al. (2008), ao analisar a diversidade genética de progênie de Piaractus mesopotamicus, obtida pelo sistema reprodutivo seminatural. O sistema reprodutivo seminatural mostrou-se eficiente, como possivelmente evidenciado neste trabalho.

Houve diminuição da variabilidade genética nos alevinos, aos 30 dias de estocagem (Tabela 3). Os valores de divergência genética, distância e identidade genética confirmaram esse resultado e evidenciaram menor divergência entre os parentais e as larvas e maior divergência entre os parentais e os alevinos. Rodriguez-Rodriguez et al. (2010) também observaram, em estoques de $B$. orbignyanus utilizados em programas de repovoamento, menor heterozigosidade nos alevinos em comparação às larvas. Segundo os autores, essa diferença pode ser

Tabela 3. Análise de variância molecular, distância e identidade genética (IG) para os diferentes agrupamentos utilizados nos parentais e nas progênies de Salminus brasiliensis.

\begin{tabular}{|c|c|c|c|c|c|}
\hline $\begin{array}{l}\text { Fonte de } \\
\text { variação }\end{array}$ & $\begin{array}{c}\text { Soma de } \\
\text { quadrados }\end{array}$ & $\begin{array}{l}\mathrm{CV} \\
(\%) \\
\end{array}$ & $\begin{array}{c}\text { Variação } \\
(\%)\end{array}$ & Distância & $\begin{array}{c}\text { Identidade } \\
\text { genética }\end{array}$ \\
\hline Grupos & \multicolumn{5}{|c|}{ Parentais $\mathrm{x}$ larvas } \\
\hline Entre & 32,760 & 1,3774 & $11,39 *$ & 0,046 & 0,954 \\
\hline Dentro & 514,600 & 10,720 & 88,61 & & \\
\hline Total & 547,360 & 12,098 & 100 & & \\
\hline Grupos & \multicolumn{5}{|c|}{ Parentais $\mathrm{x}$ alevinos } \\
\hline Entre & 30,125 & 1,3497 & $13,66^{*}$ & 0,061 & 0,941 \\
\hline Dentro de grupos & 409,375 & 8,5286 & 86,34 & & \\
\hline Total & 439,500 & 9,8784 & 100 & & \\
\hline Grupos & \multicolumn{5}{|c|}{ Larvas $\mathrm{x}$ alevinos } \\
\hline Entre & 46,900 & 0,9440 & $9,36 *$ & 0,031 & 0,969 \\
\hline Dentro de grupos & 712,750 & 9,1378 & 90,64 & & \\
\hline Total & 759,650 & 10,081 & 100 & & \\
\hline
\end{tabular}

*Significativo a $5 \%$ de probabilidade. consequência do canibalismo inicial presente nessa espécie, das condições ambientais de crescimento, da fase de aclimatação ou da mortalidade aleatória. É provável que esses fatores tenham influenciado a progênie de $S$. brasiliensis, já que, nas fases iniciais de crescimento, também há elevado canibalismo e alta mortalidade (Schütz \& Nuñer, 2007; Flora et al., 2010). Conforme Esteves \& Pinto Lobo (2001), o dourado é um peixe que ocupa o topo da cadeia alimentar, e é considerado piscívoro ou ictiófago por excelência.

No gráfico de dispersão em coordenadas principais (Figura 1) é apresentada a distribuição da progênie nas duas fases, e identifica os dois grupos de indivíduos. Os cinco casais de reprodutores contribuíram com as larvas, com dois dias de idade. Para os alevinos com 30 dias de idade, apenas dois reprodutores contribuíram com a maior parte dos indivíduos do grupo. Provavelmente, os alevinos provenientes dos outros quatro casais não suportaram a pressão causada pelo canibalismo e pelas condições ambientais.

Há diferenças genéticas em uma mesma progênie durante as diferentes fases de crescimento. Esta informação é importante para programas de repovoamento, em que normalmente apenas a análise

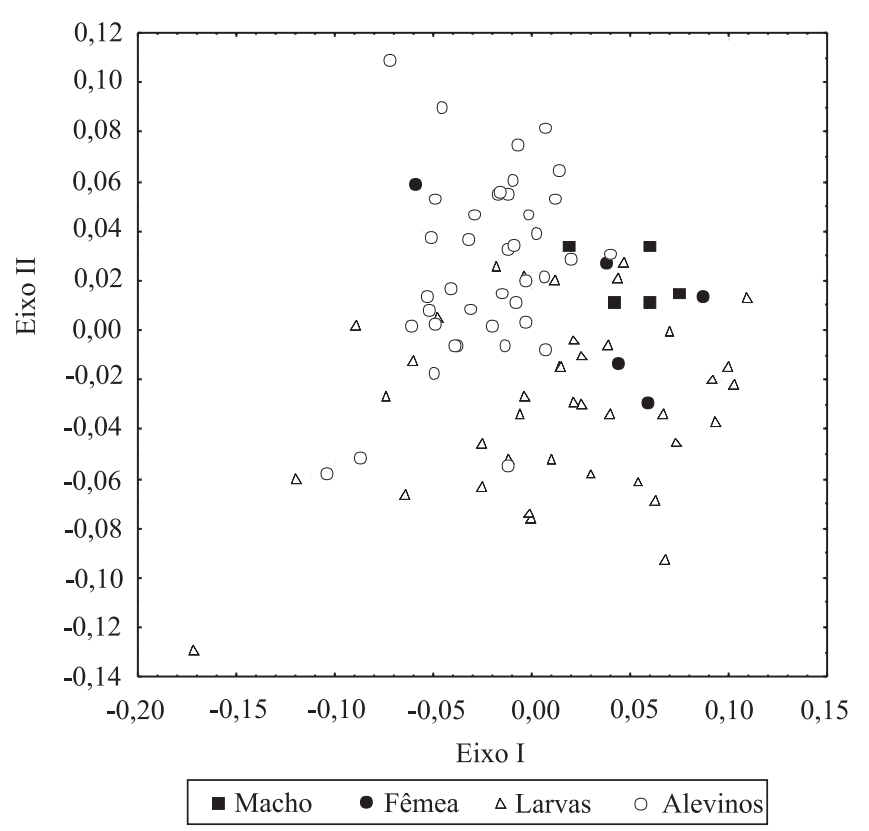

Figura 1. Gráfico de dispersão em coordenadas principais do estoque de reprodutores (machos e fêmeas) de Salminus brasiliensis e suas respectivas progênies (larvas de 2 dias e alevinos de 30 dias). 
genética das larvas é indicativa da variabilidade genética das progênies a serem liberadas nos rios. Sugere-se a avaliação da diversidade genética das progênies de $S$. brasiliensis utilizadas em programas de repovoamento em duas fases: nas larvas, que oferecerá uma visão geral das características genéticas da nova geração, e aos 60 ou 90 dias (dependendo do manejo e das condições ambientais do ecossistema em que serão liberadas), o que permitirá estimar a variabilidade genética dos indivíduos que serão liberados. Para isto, marcadores moleculares como o RAPD e microssatélites mostram-se eficientes e confiáveis.

\section{Conclusões}

1. A variabilidade genética do estoque de reprodutores de Salminus brasiliensis é alta, por isso, podem ser utilizados em programas de repovoamento.

2. Há perda de variabilidade genética entre as fases larvas e alevinos.

3. Há diferenciação genética entre as larvas e os alevinos de $S$. brasiliensis.

\section{Referências}

AgOSTINHO, A.A.; THOMAZ, S.M.; GOMES, L.C. Conservação da biodiversidade em águas continentais do Brasil. Megadiversidade, v.1, p.70-78, 2005.

BARBIERI, G.; SALLES, F.A.; CESTAROLLI, M.A. Reproductive and nutritional dynamics of Salminus maxillosus Valenciennes, 1849 (Pisces, Characidae) at Mogi Guaçu river, state of São Paulo, Brazil. Acta Scientarium, v.23, p.441-444, 2001.

ESTEVES, K.E.; PINTO LOBO, A.V. Feeding pattern of Salminus maxillosus at Cachoeiras de Emas, Mogi Guaçu river (São Paulo State Southeast Brazil). Revista Brasileira de Biologia, v.61, p.267-276, 2001.

EXCOFFIER, L.; LAVAL, G.; SCHNEIDER, S. Arlequin (version 3.0): an integrated software package for population genetics data analysis. Evolutionary Bioinformatics Online, v.1, p.47-50, 2005.

FLORA, M.A.D.; MASCHKE, F.; FERREIRA, C.C.; PEDRON, F.A. Biologia e cultivo do dourado (Salminus brasiliensis). Acta Veterinária Brasílica, v.4, p.7-14, 2010.

JACOMETO, C.B.; LOPERA-BARRERO, N.M.; RODRIGUEZ-RODRIGUEZ, M.P.; GOMES, P.C.; POVH, J.A.; STREIT JUNIOR, D.P.; VARGAS, L.; RESENDE, E.K.; RIBEIRO, R.P. Variabilidade genética em tambaquis (Teleostei: Characidae) de diferentes regiões do Brasil. Pesquisa Agropecuária Brasileira, v.45, p.481-487, 2010.

LEGENDRE, P.; ANDERSON, M.J. Program DistPCoA. Montréal: Université de Montréal, 1998. 10p.
LIMA, F.C.T.; MALABARBA, L.R.; BUCKUP, P.A.; SILVA, J.F.P.; VARI, R.P.; HAROLD, A.; BENINE, R.; OYAKAWA, O.T.; PAVANELLI, C.S.; MENEZES, N.A.; LUCENA, C.A.S.; MALABARBA, M.C.S.L.; LUCENA, Z.M.S.; REIS, R.E.; LANGEANI, F.; CASSATI, L.; BERTACO, V.A.; MOREIRA, C.; LUCINDA, P.H.F. Genera Incertae Sedis in Characidae. In: REIS, R.E.; KULLANDER, S.O.; FERRARIS, C.J. (Ed.). Check list of the freshwater fishes of South and Central America. Porto Alegre: Edipucrs, 2003. p.106-156.

LOPERA-BARRERO, N.M. Diversidade genética de Brycon orbignyanus em sistema reprodutivo seminatural. 92p. 2007. Tese (Doutorado) - Universidade Estadual de Maringá, Maringá.

LOPERA-BARRERO, N.M.; POVH, J.A.; RIBEIRO, R.P.; GOMES, P.C.; JACOMETO, C.B.; LOPES, T. da S. Comparación de protocolos de extracción de $\mathrm{ADN}$ con muestras de aleta y larva de peces: extracción modificada con cloruro de sodio. Ciência e Investigación Agraria, v.35, p.77-86, 2008.

LOPERA-BARRERO, N.M.; RIBEIRO, R.P.; VARGAS, L.; POVH, J.A.; LOPES, T.S.; OLIVEIRA, S.N.; GOMES, P.C. Diversidad genética de Piaractus mesopotamicus utilizado em programas de repoblación. Archivos de Zootecnia, v.59, p.51-62, 2010a.

LOPERA BARRERO, N.M.; VARGAS, L.; SIROL, R.N.; RIBEIRO, R.P.; POVH, J.A.; MANGOLIN, C.A. Caracterização genética de Brycon orbignyanus utilizando o sistema seminatural. Arquivo Brasileiro de Medicina Veterinária e Zootecnia, v.62, p.184-191, 2010b.

LOPERA-BARRERO, N.M.; VARGAS, L.; SIROL, R.N.; RIBEIRO, R.P.; POVH, J.A.; STREIT JUNIOR, D.P.; GOMES, P.C. Diversidad genética y contribución reproductiva de una progenie de Brycon orbignyanus en el sistema reproductivo seminatural, usando marcadores microsatélites. Agrociencia, v.44, p.171-181, 2010c.

LOPES, C.M.; ALMEIDA, F.S.; ORSI, M.L.; BRITTO, S.G.C.; SIROL, R.N.; SODRÉ, L.M.K. Fish passage ladders from Canoas Complex - Paranapanema River: evaluation of genetic structure maintenance of Salminus brasiliensis (Teleostei: Characiformes). Neotropical Ichthyology, v.5, p.131-138, 2007.

MILLER, M.P. Tools for population genetic analyses (TFPGA) 1.3: a Windows program for the analysis of allozyme and molecular population genetic data. Logan: Utah State University, 1997.

MILLER, M.P.; MANTEL-STRUCT: a program for the detection of population structure via mantel tests. Journal of Heredity, v.90, p.258-259, 1999.

NEI, M. Estimation of average heterozygosity and genetic distance from a small number of individuals. Genetics, v.89, p.583-590, 1978.

ORTEGA-VILLAIZÁN ROMO, M. Del M.; ARITAKI, M.; TANIGUCHI, N. Pedigree analysis of recaptured fish in the stock enhancement program of spotted halibut Verasper variegates. Fisheries Science, v.72, p.48-52, 2006.

PAMPONET, V. de C.C.; CARNEIRO, P.L.S.; AFFONSO, P.R.A.M.; MIRANDA, V.S.; SILVA JÚNIOR, J.C.; OLIVEIRA, C.G. de; GAIOTTO, F.A. A multi-approach analysis of the genetic diversity in populations of Astyanax aff. bimaculatus Linnaeus, 
1758 (Teleostei: Characidae) from Northeastern Brazil. Neotropical Ichthyology, v.6, p.621-630, 2008.

POVH, J.A.; LOPERA BARRERO, N.M.; RIBEIRO, R.P.; LUPCHINSKI JUNIOR, E.; GOMES, P.C.; LOPES, T.S. Monitoreo genético en programas de repoblamiento de peces mediante marcadores moleculares. Ciencia e Investigación Agraria, v.35, p.5-15, 2008.

RAYMOND, M.; ROUSSET, F. An exact test for population differentiation. Evolution, v.49, p.1280-1283, 1995.

RODRIGUEZ-RODRIGUEZ, M. del P.; LOPERA-BARRERO, N.M.; RIBEIRO, R.P.; POVH, J.A.; VARGAS, L.; SIROL, R.N.; JACOMETO, C.B. Diversidad genética de piracanjuba usada en programas de repoblación con marcadores microsatélites. Pesquisa Agropecuária Brasileira, v.45, p.56-63, 2010.

SANCHES, A.; GALETTI JUNIOR, P.M. Genetic evidence of population structuring in the neotropical freshwater fish Brycon hilarii (Valenciennes, 1850). Brazilian Journal of Biology, v.67,p.889-895, 2007.

SCHÜTZ, J.H.; NUÑER, A.P.O. Growth and survival of dourado Salminus brasiliensis (Pisces, Characidae) post-larvae cultivated with different types of food and photoperiods. Brazilian Archives of Biology and Technology, v.50, p.435-444, 2007.

SIROL, R.N.; BRITTO, S.G. Conservação e manejo da ictiofauna: repovoamento. In: NOGUEIRA, M.G.; HENRY, R.; JORCIN, A. (Ed.). Ecologia de reservatórios: impactos potenciais, ações de manejo e sistemas em cascata. São Carlos: Rima, 2006. p.275-284.

STATSOFT. Statistica (data analysis software system). Version 7.1. 2005. Available at: <www.statsoft.com>. Accessed on: 20 Oct. 2009.

WILLIAMS, J.G.; KUBELIK, A.R.; LIVAK, K.J.; RAFALSKI, J.A.; TINGEY, S.V. DNA polymorphism amplified by arbitrary primers are useful as genetic markers. Nucleic Acids Research, v.18, p.6531-6535, 1990.

YEH, F.C.; BOYLE, T.Y.Z.; XIYAN, J.M. PopGene version 131: Microsoft Window-based freeware for population genetic analysis. Edmonton: University of Alberta and Center for International Forestry Research, 1999.

ZANIBONI-FILHO, E. Piscicultura das espécies nativas de água doce. In: POLI, C.R.; POLI, A.T.B.; ANDREATTA, E.; BELTRAME, E. Aqüicultura: experiências brasileiras. Florianópolis: UFSC, 2004. p.337-369.

Recebido em 13 de setembro de 2010 e aprovado em 17 de janeiro de 2011 